\title{
Outward Medical Tourism: A Case of UAE
}

\author{
Gouher Ahmed1, Nabeel Al Amiri², Wajahat Khan ${ }^{3}$ \\ ${ }^{1}$ College of Business Studies, Skyline University College, University City of Sharjah, Sharjah, UAE \\ ${ }^{2}$ Tawam Hospital, Al Ain, UAE \\ ${ }^{3} \mathrm{Al}$ Ghurair University, Dubai, UAE \\ Email: gouher@usa.net, alamirinabeel@hotmail.com,wajahat@agu.ac.ae
}

How to cite this paper: Ahmed, G., Al Amiri, N. and Khan, W. (2018) Outward Medical Tourism: A Case of UAE. Theoretical Economics Letters, 8, 1368-1390. https://doi.org/10.4236/tel.2018.87088

Received: February 11, 2018

Accepted: May 25, 2018

Published: May 28, 2018

Copyright $\odot 2018$ by authors and Scientific Research Publishing Inc. This work is licensed under the Creative Commons Attribution International License (CC BY 4.0).

http://creativecommons.org/licenses/by/4.0/

Open Access

\begin{abstract}
Medical tourism is the travelling of people to a different place to receive treatment for a disease, an ailment, or a condition, or to undergo a surgical procedure. It is a form of international trade in services. Medical tourism allows some countries to export their products and services to other countries and improve their balance of payments. It also gives many advantages to the travelers, such as getting high quality of medical treatment that is not available in their home country or to get it at a low cost. As a part of its economic diversification strategy, the UAE has invested heavily in establishing world-class medical facilities, standard, with high treatment standards for citizens as well as for people from outside especially from the middle-east and Africa, who come to UAE on the medical tourist visas, which is a paradox. The study is of outward tourism is set to study in terms of numbers, ailments, procedure and destination lists and efficiency. The study found many interesting trends of medical tourism in the outward of the UAE, some of these trends are positive and are in need to be boosted by health authorities to build a better and profitable healthcare industry in the country. In sum, the study is a study of the dynamics of outward medical tourism with the help of a sample of 232 medical tourists from UAE to other countries. It is found that there is a rising trend of outward medical tourism which can be well taken care by raising the status of medical and treatment facilities in the UAE to the global level.
\end{abstract}

\section{Keywords}

Medical Tourism, Healthcare Tourism, Medical Travel, Medical Consumers Abroad and United Arab Emirates (UAE)

\section{Introduction}

Today, globalization is the norm and world-wide trend in all fields, in the medi- 
cal industry, globalization affects business by attracting patients, health care providers such as doctors and nurses, medical technology, and investments to cross borders for a better health and business outcome. The travelling of people from their country to other countries seeking medical treatment is called in literature as "medical tourism", which is a rising form of tourism more so in the newly developed nations like the UAE with rising national and per capita incomes. Their medical tourism destinations are likely to be medically well endowed the USA, UK, and other medically established nations that command good medical reputation.

The UAE too, in its development journey of last five decades or so, has come to enjoy good medical reputation with world standard medical infrastructure and treatment facilities, which are well conducive to medical tourism, yet, the UAE government spent a large chunk of its total healthcare budget to send its Emirati people abroad for medical treatment. Research shows that about one-third of UAE nationals, if seriously ill, would seek treatment abroad. According to a Korean study, the Emiratis were the second largest number among all foreign visitors to Korea, and nearly, $2.1 \%$ of them were UAE nationals who considered themselves as medical tourists [1]. The study found that the primary determinant for selecting specific hospital and the country as a medical destination was word-of-mouth information, followed by advanced medical care and technology, and support from government and medical agencies. The UAE aspires to be No. 1 in every field, seeking to overcome the medical gap to give its citizens world-class facilities and treatment not only to retain its patients aspiring to go abroad but also to inward tourist inflows from Asia and Africa, especially in Dubai and Abu Dhabi, as a global medical hub, with the Collaboration of American Hospital in Dubai with Mayo Clinic, and the presence of Cleveland Clinic in Abu Dhabi and many others to name in the country.

Hence, this study is addressed to the dynamics of the UAE's outward medical tourism.

\section{Review of Literature}

\subsection{History of Medical Tourism}

Studies on medical tourism abound, starting from the ancient fruits to the present, in several tourism aspects. The first comprehensive system of medical care was founded by the Greeks with people from far off areas visiting the Greek empire temples like the Asclepia. "Asclepius the god of medicine", Sanctuary of Zeus in Olympia and the Temple of Delphi for healing several hot-water baths and springs gained popularity in Rome when it became a global power. These baths became commercial and social networking centers for the rich and the elite. Later, during the Renaissance times, in 1326, iron-rich hot springs were discovered in France near Ville d'Eaux (Town of Waters). The treatment with hot water became popular and it was called "spa" derived from the Roman phrase "salude per aqua" which means "health through waters" during the $18^{\text {th }}$ 
and $19^{\text {th }}$ centuries, several Europeans and Americans continued to travel to spas and health retreats to cure various diseases like tuberculosis. During the $20^{\text {th }}$ century, more effective and modern treatments were discovered in some developed countries such as the United States and Europe. Thereafter, other countries in Asia and Latin America such as India, Cuba, Thailand, and Singapore became the famous destination for medical tourism [2].

\subsection{Definition of Medical Tourism}

It is important to begin by defining what is meant by medical tourism. The Medical Tourism Association's definition of the term medical tourism is defined as "Medical Tourism is where people who live in one country travel to another country to receive medical, dental and surgical care while at the same time receiving equal to or greater care than they would have in their own country, and are traveling for medical care because of affordability, better access to care or a higher level of quality of care. "Domestic Medical Tourism" is where people who live in one country travel to another city, region or state to receive medical, dental and surgical care while at the same time receiving equal to or greater care than they would have in their own home city, and are traveling for medical care because of affordability, better access to care or a higher level of quality of care" [3].

The detailed study of the medical and wellness tourism sectors in the book Health and Wellness Tourism, by the authors Smith and Puczko' (2009), defined medical tourism as “... travel to destinations to undergo medical treatments such as surgery or other specialist interventions ... Medical tourism [...] can have two major forms: surgical and therapeutic. There is a clear distinction between the two. Surgical certainly involves certain operations(s), whereas therapeutic means participating in healing treatments" [4].

Horowitz and Rosensweig (2008), attempts to define the contemporary medical tourism market and differentiate it from the more historical model of "international medical travel" their definition emphasizes the direction or flow of travel between industrialized nations and developing nations, and suggests that medical tourism specifically relates to patients traveling from industrialized to less developed countries[5].

According to Jagyasi (2008) "Medical Tourism is the set of activities in which a person travels often long distance or across the border, to avail medical services with direct or indirect engagement in leisure, business or other purposes" [6].

Carrera and Bridges (2006, p.447), for example, define health tourism as-the organized travel outside one's local environment for the maintenance, enhancement or restoration of an individual's well-being in mind and body [7].

For our purpose, we define medical tourism as when consumers decide to travel another country with the intention of receiving medical treatment.

Individual countries have their own definitions and there is no "official" definition of medical tourism-so regional or country-specific definitions must be 
inferred from what governments are actually supporting or promoting.

Medical tourism is the travelling of people to a different place to receive treatment for a disease, an ailment, or a condition, or to undergo a surgical procedure. Another term "wellness tourism" is used to describe people who travel abroad to receive treatment that maintain their health wellbeing [3]. Some authors claim that "wellness tourism" involves spa and relaxation treatments while "health tourism" encompasses all treatments including cosmetic and essential surgery.

In this paper, we use the term medical tourism over health tourism because the phrase is being used by the general public, media and the UAE people for the medical tourism to receive medical treatment or surgery from abroad.

Many other terms are used to describe travelling for receiving medical treatment, as shown in Table 1 .

\subsection{Medical Tourism as an International Business}

International business is defined as the cross-border commercial activities that include complexities in different legislation, political environments, cultures, societies, and other factors. Medical tourism is a form of international trade in services as defined by the World Trade Organization (WTO). The General Agreement on Trade in Services (GATS) defines four modes of supply through which services can be traded [8] (Table 2).

Medical tourism falls under Mode 2, which involves the movement of persons to the country where the services are provided. The medical tourism country is the "exporter" of service while the patient's home country is the "importer" of the service.

Table 1. Terms used to describe travelling for receiving medical treatment.

\begin{tabular}{cc}
\hline Term & Definition \\
\hline $\begin{array}{c}\text { Medical travel } \\
\text { Domestic medical tourism }\end{array}$ & A patient travel from home to a different country for invasive medical treatment \\
$\begin{array}{c}\text { Cross-border medical travel } \\
\text { International patients }\end{array}$ & A patient travel to a nearby country for treatment \\
Transplant tourism & A patient may be expatriate or people on vacation and who seek medical treatment \\
\end{tabular}

Table 2. Modes of medical supply.

\begin{tabular}{|c|c|c|}
\hline Mode & Definition & Example \\
\hline Mode 1 & Cross-border & $\begin{array}{l}\text { Users receive services from abroad through the telecommunications or postal network. Such supplies may } \\
\text { include consultancy or market research reports, tele-medical advice, distance training, or architectural drawings }\end{array}$ \\
\hline Mode 2 & Consumption abroad & Consumers have moved abroad as tourists, students, or patients to consume the respective service \\
\hline Mode 3 & Commercial presence & $\begin{array}{l}\text { The service is provided by a locally-established affiliate, subsidiary, or office of a foreign-owned and controlled } \\
\text { company (bank, hotel group, construction company, etc.) }\end{array}$ \\
\hline Mode 4 & $\begin{array}{l}\text { Movement of natural } \\
\text { persons }\end{array}$ & $\begin{array}{l}\text { A foreign national provides services within A as an independent supplier (e.g., consultant, health } \\
\text { worker) or employee of a foreign service firm (e.g. consultancy, hospital, construction company) }\end{array}$ \\
\hline
\end{tabular}


In 1989, the Organization for Economic Cooperation and Development (OECD) report noted that trade in health services provided developing countries with a competitive opportunity by giving them the abundance of labor and availability of capital and skills in medicine [9].

In 1997, the United Nations Conference on Trade and Development (UNCTAD), which monitors trade between countries, noted for the first time that trade in services, including health services, could be beneficial for developing countries [10].

Medical tourism has several advantages for the exporter Countries [11]. It allows them to export their products to other countries and improve their balance of payments. Furthermore, it can improve the health labor market in these countries, stemming a brain drain of health care professionals and getting international goodwill [12].

On the other hand, medical tourism has many advantages for medical tourist such as they can receive a higher quality care with lower cost than in their home country, they can reach quickly the care and avoid long waiting list in their home countries, and get more privacy and confidentiality. Medical tourism has some significant health disadvantages for patients such as the medical follow-up cannot be maintained abroad and it has to continue in the home country [12]. On the other hand, estimations suggest that Medical tourist usually spend twice as much than standard tourists [13]. For example, in Malaysia, healthcare services recorded the highest among all the spending components including airfares, accommodation, organized tours, and shopping [14].

Medical tourism is market driven and it is made by the complex interactions of medical, economic, social and political forces. Medical tourist consumers begin a world-wide journey for health care for lower costs, less waiting times, and easy access medical services that aren't available in their country or not up to the standards.

One important theory that used to conceptualize the conditions which are important when conducting international business is Porter's diamond of national competitive advantage. It is a modern international trade theory that shows four important components are included in the shape of a two-dimensional diamond [15]. These include demand conditions, factor conditions, related and supporting industries, and firm strategy, structure and rivalry. Other two elements that include chance and government were later added to the conceptualization.

Medical tourism growth is linked to the four components of the theory. First, the demand for medical services increases as the aging population increases. In many countries, this demand cannot be met because the healthcare in private hospitals is expensive and the numbers of people who do not subscribe to healthcare insurance increases, and the public waiting lists for medical treatment are too long. Secondly, other basic factors such as warm and pleasant environment, geographic location, and technology are considered as an advantage for 


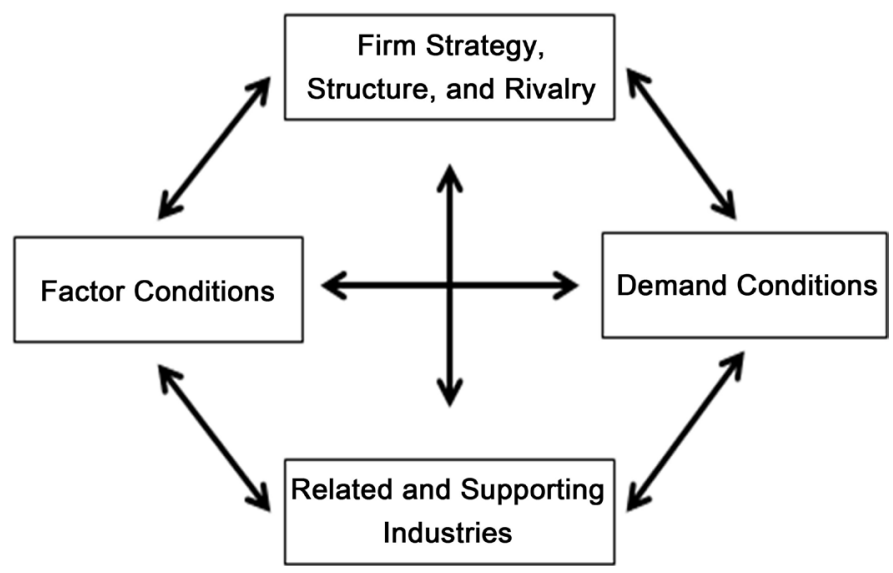

Figure 1. Porter's diamond of national competitive advantage. Source: Porter, M.E. [1990] (Figure 1). The competitive advantage of nations, Harvard Business Review, March-April, pp. 73-93.

medical tourists. Thirdly, medical tourism relies on related and supporting industries and infrastructure such as airlines, hotels and transportation inside the medical tourism destination. Last, the individual success of hospitals participating in medical tourism is dependent on their strategy, structure and rivalry such as providing high quality service and good customer satisfaction [15].

Each medical tourism destination has its unique factors that explain its competitive attractiveness for medical tourists. For example, in case of Malaysia, Singapore, Geography was found to be an important factor which has a positive impact on the satisfaction of patients who come from different locations such as Indonesia. In the case of India, which became a favorite destination for medical tourists mostly from the Middle East and South Asian countries. In brief, this was due to the lowest medical cost advantage, the best doctors available, English speaking, and quality facilities available in hospitals and not much waiting time.

\subsection{International Trends of Medical Tourism}

Although medical tourism was small in comparison to other service trade including the trade in tourism services, the World Health Organization (WHO) described it as a growing trend with enormous economic implications. It was the fastest-growing segment of tourist markets of developing countries such as Thailand, Malaysia, and India [16].

Before, wealthy patients travelled from developing countries to developed countries for high quality medical care. Now, the trend was changed and patients from developed countries such as USA and Europe are traveling to developing countries such as India [17].

According to a 2008 estimate, the medical tourism business is in operation in 28 countries globally. The most popular destinations for medical tourism are third world countries such as Thailand, India, Malaysia, the Philippines, Singapore, Jordan, Turkey, Hungary, Mexico, Cuba, Chile and South Africa, while a few other medical tourist hubs are emerging in Dubai and Eastern Europe [18].

Those patients are travelling to receive high quality medical care at affordable 
prices. For example, in 2007, hospitals in Argentina, Singapore or Thailand charged $\$ 8000$ to $\$ 12,000$ for a partial hip replacement, where United States and Europe hospitals were charging one and half the price [17].

In UK, a survey conducted in 2012 revealed that 42 percent of the UK patients went abroad for cosmetic surgery, 32 percent for dental treatment, 9 percent for obesity surgery, and 4 percent for both infertility treatment and orthopedic surgery [19].

One study published in 2012 surveyed a wide range of global consumers on their experiences of medical tourism. q-Sample's from online traveler panel was used to reach a broad group of consumers [11]. The study showed that when given a choice for consumers between cost, time, and availability for going to another country for medical tourism, $44 \%$ mentioned cost most frequently, 33\% mentioned availability, $19 \%$ mentioned time or speed of treatment, and $4 \%$ mentioned other reasons such as expertise [20].

Moreover, healthcare hotels which combine hotel, hospital, and health care, are a superior proxy for common medical clinics. Three distinctive attributes of health care hotels were identified by researchers that can maximize the effectiveness of medical tourism destination efforts to attract new travelers. These attributes include 1) monetary and convenience such as receiving various healthcare services at a single location and at lower prices or being able to stay in the same facility with family/friends, 2) personal security, and 3) the availability of services [21].

Medical tourists are often accompanied by family members, friends, or other caregivers who assume a variety of informal care-giving roles and responsibilities such as offering physical assistance, providing emotional support, record keeping, and aiding in decision-making. Some advice given by some Canadian informal care givers to protect their health and safety by developing an informational tool to prepare potential caregiver companions of medical tourists for their role. Those advices include the 1) assessing and 2) avoiding exposure to identifiable risks, 3) anticipating the care needs of medical tourists, 4) becoming familiar with logistics related to travel and recovery, and 5) protecting their own health [22].

According to literature review study conducted in 2016 show that motivation and decision making process to travel abroad for medical tourism is complex and we need to gain insight into why patients from countries with public health-care systems such as the UK choose to travel abroad [23].

There have been many questions about the training, qualifications, and competence of health care professionals and quality and safety of the medical care provided overseas [18]. In response to such concerns, hospitals in medical tourism destinations sought a special accreditation-quality assessment by independent and international organizations such as the Joint Commission International from the United States and Quality Healthcare Advice Trent Accreditation in the UK [24].

Medical tourism involves a wide range of stakeholders seeking profits. Those 
stakeholders include hospitals, health care providers, insurance providers, intermediaries, governments, and others.

As per a study published by Deloitte, the reported number of medical travelers is nearly 750,000 patients, who traveled overseas from the US for medical treatment in 2007 , and the figure increased to nearly 1.5 million in 2008. One estimate indicates that the worldwide revenue for medical tourism was about $\$ 60$ billion in 2006. One projection estimates that US patients will spend more than $\$ 40$ billion for medical treatment abroad by 2017 [25].

McKinsey published an important study of medical tourism in 2008. According to the study, medical tourism reports do not show the accurate numbers of travelers as per the medical tourist definition "People who travelled abroad mainly to receive medical treatment or surgery" [18]. The available reports may have included other category of patients who received treatment in a foreign country while they are in regular tourism trip, patients live or work in medical tourism country, patients who travelled to other geographic countries, or people who travelled for wellness tourism such as massage and relaxation [18].

The medical tourist may be affluent and people of adequate means which drives home the point for building a competitive and comprehensive public health care system for the people of means.

Patient satisfaction is an important dimension of healthcare treatment. Relatively little is known about the experience and satisfaction of medical tourists. According to McKinsey study, patients report generally high satisfaction with the quality of care received overseas, but it is not clear that this can be extrapolated outside of the US and to a range of treatments [19]. A study conducted in UK showed 90 percent of participants would definitely or probably go abroad for treatment again and the same number would recommend travelling abroad for treatment to a friend or relative [19].

The global Medical tourism industry faces a major problem of lack of legal constitution in the service providing country. Thus, the patients are at risk while they visit a foreign country for obtaining healthcare. Besides, most patients do not have information about the technical matter for the treatment [26].

Meghani (2013) has studied the case of UK patients going to India for medical care. She aimed to recognize the role of individuals, organizations, and nations as morally significant in shaping the ethical dilemma. She highlighted three morally ethical arguments against this case of medical tourism. These ethical arguments included the feature of the United Kingdom's health care system such as long waiting time for serious but non-urgent cases and the reliance of the United Kingdom on India to meet its citizens' medical needs. Besides, it is better if the poor in India are providing with increased access to medical care [27].

\subsection{UAE as Medical Tourism Destination}

Medical tourism in UAE is cited as one of the fastest growing industries. The UAE has invested billions of dollars in the healthcare sector, establishing internationally accredited hospitals and clinics such as Dubai Healthcare City the 
world's first healthcare free zone, The Cleveland Clinic and Moorfields Hospital in Dubai and Abu Dhabi. The country strategy focuses on building an excellent health system that focuses on highly qualified medical practitioners, building world class hospitals and presenting medical packages that include visa, hotel stay, transportation and other activities for health care travelers from outside the country. The marketing strategy will be implemented in various languages and will target patients from Russia, CIS countries, South Asia and neighboring GCC countries. In 2014, Dubai has approved a comprehensive strategy to further strengthen the country leading position in the medical tourism industry [28].

In 2016, according to the Medical Tourism Index (MTI), Dubai was ranked as the $16^{\text {th }}$ preferred destination for Medical Tourism with an overall MTI Score 67.54 and Abu Dhabi as $25^{\text {th }}$ with an overall MTI Score 63.65 [29]. Dubai is on the top of the list among GCC and Middle East countries. Comparing Dubai MTI score with other famous medical tourism destinations scores such as Germany (71.90), France (71.22), and India (72.10) shows that the gap is not wide. In addition, in 2016, The UAE is leading the world in having the largest number of accredited health organizations by the JCI "The world's largest healthcare accreditor" [30].

Medical tourism may draw upon other economic sectors in Dubai such as hotels, transportation, restaurants, and shopping centers. Their collective impact is a trickle-down of benefits that support "whole-of-country" approach to economic development. As an evidence, the Dubai Health Authority (DHA's) revenue figure for the first 6 months of 2015 for the industry is U.S.\$272 million-an increase of over $50 \%$ on its twelve-month total for 2012 [31]. The revenue of medical tourism is expected to grow to US\$ 710 million by 2020 . Comparing Dubai's medical tourism revenue in the total global medical tourism (US\$ 50 billion to US\$ 60 billion a year) shows that Dubai is still a small player in the global medical tourism market [32].

In this, interesting global medical tourism scenario, the present study seeks to study the trends and characteristics feature of the UAE's outward medical tourism.

\section{The Study Objectives, Methodology and Data}

The main purpose of this research is to understand the trends of medical tourism abroad among UAE people. It will provide insight into the preferred destinations of UAE nationals, frequency of visits, lengths of stay, type of treatments received abroad, and the activities combined with medical trip. Further, it will investigate factors influencing decision making for seeking overseas medical treatment or services.

The research will answer the following main questions:

- To study the global trends in medical tourism as a fast-moving trade;

- To know the factors influencing Emirate's in decision making for seeking overseas medical treatment or services; 
- To examine the expected future of the outward medical tourism among the people of the UAE.

\section{Methodology}

\subsection{Study Design}

A combination of face-to-face interview and self-administration technique was adopted to collect the information for the study.

\subsection{Population and Sampling}

In order to collect the primary data for this study a structured questionnaire was used. The target population for the study was the medical customers who have visited outside UAE for any medical service or treatment. In the absence of sampling framework, a snowball technique was used for selecting and contacting the participants in this study. The target sample size for the study was determined as 250 . After completing the target sample and after initial scrutiny a total of 232 questionnaires was found complete and were used for the analysis in this study.

The questionnaires were distributed and collected after due verification by a team of trained investigators. The study pertains to year 2017.

\subsection{Survey Instrument}

The questionnaire was developed through a thorough literature review and with the help of focus group discussions. The questionnaire mainly consisted of two sections. The first section mainly includes, questions related to the background information of the respondents, preferred destination, type of medical treatment/services, and their stay. However, in the second section of the questionnaires, 15 questions pertaining to motivational factors were listed.

The respondents were asked to rate on a five point Likert type scale ( 1 as not important to 5 as most important).

\subsection{Ethical Consideration}

The Ethics of medical confidentiality adhered to all the study times.

\section{Data Analysis}

\subsection{Background Information on Medical Tourists}

Table 3 shows the details about the background information of the medical tourists. A little less than one-third (31\%) of the respondents who seek oversees medical help in the past were 40 years of age or less while about $27 \%$ were in the age group of 41 to 50 years of age about $24 \%$ were in 51 to 60 years old group and about $18 \%$ medical tourists were above 60 years of age.

The statistics obtained from the sample of 232 medical tourists pertain to their personal factors of age, gender, education and their Emirate (7) and their medical destinations (7 nations) number of trips, tourism sources, treatments, length 
Table 3. Background information about the medical tourists.

\begin{tabular}{|c|c|c|}
\hline & Number & Percentage \\
\hline \multicolumn{3}{|l|}{ Age (in years) } \\
\hline$\leq 40$ years & 72 & 31.0 \\
\hline $41-50$ years & 63 & 27.2 \\
\hline $51-60$ years & 56 & 24.1 \\
\hline More than 60 years & 41 & 17.7 \\
\hline \multicolumn{3}{|l|}{ Gender } \\
\hline Male & 168 & 72.4 \\
\hline Female & 64 & 27.6 \\
\hline \multicolumn{3}{|l|}{ Qualification } \\
\hline Up to secondary & 77 & 33.2 \\
\hline Bachelor degree & 104 & 44.8 \\
\hline Postgraduate/master degree & 51 & 22.0 \\
\hline \multicolumn{3}{|l|}{ Residence } \\
\hline Abu Dhabi & 74 & 31.9 \\
\hline Dubai & 65 & 28.0 \\
\hline Sharjah & 57 & 24.6 \\
\hline Ajman & 24 & 10.3 \\
\hline Umm Al Quwain & 8 & 3.4 \\
\hline Ras Al Khaimeh & 2 & 0.9 \\
\hline Fujairah & 2 & 0.9 \\
\hline Total number of respondents & 232 & 100.0 \\
\hline
\end{tabular}

of study and other activities (Table 3 \& Table 4). There are 15 determinants taken into account by a discerning outbound medical tourist in the choice of their medical destination, (Table 9). The statistical tools deployed are, chi-square, ANOVA, regression and factor analysis for a view of 'association of variables and strengths' of the 15 determinant factors in medical tourism decision making.

The majority of the sample medical tourists (72.4\%) were males and about $28 \%$ females. In terms of qualification, one-third of the participants were having up-to secondary level, $45 \%$ had bachelor degree while $22 \%$ had a Master degree as their educational qualification. Most of the respondents were from Abu Dhabi (32\%), Dubai (28\%), and Sharjah (25\%) while about $16 \%$ of them were residing in other emirates of UAE (Table 3 ).

The relative affluence of the sample respondents can be found from their high educational qualification of degree and the high GNI per capita income of US $\$ 72.98$ a year.

Yet, it is to be known whether the UAE's outward medical tourism is considered a status symbol.

\subsection{Travel Behaviors of Medical Tourists}

Table 4 presents the travel behavior of medical tourists. The most preferred 
Table 4. Travel behaviors of medical tourists.

Number Percentage

[A] Country visited for medical trip

USA

Germany

Other European country

$$
\begin{gathered}
\text { Thailand } \\
\text { India }
\end{gathered}
$$$$
\text { Singapore }
$$

UK

$\begin{array}{cc}45 & 19.4 \\ 56 & 24.1 \\ 13 & 5.6 \\ 47 & 20.3 \\ 26 & 11.2 \\ 32 & 13.8 \\ 13 & 5.6\end{array}$

[B] No. of times travelled abroad for medical trip

One time

$\begin{array}{ll}70 & 30.2 \\ 91 & 39.2 \\ 71 & 30.6\end{array}$

Three times or more

[C] Time of last medical tourism trip

$\begin{array}{ccc}<\text { One year } & 76 & 32.8 \\ 1 \text { - } 3 \text { years } & 117 & 50.4 \\ \text { More than 3 years } & 39 & 16.8\end{array}$

[D] Source of information about the medical tourism destination

$$
\text { Recommended by doctor }
$$

Recommended by government

Friend/s

Internet

Television

Medical tourism guide

$\begin{array}{ll}57 & 23.7 \\ 78 & 35.3 \\ 69 & 32.3 \\ 28 & 6.0 \\ 2 & 0.9 \\ 5 & 2.2\end{array}$

[E] Type of medical treatment/service received

$\begin{array}{ccc}\text { Surgery } & 49 & 21.1 \\ \text { Medications } & 61 & 26.3 \\ \text { Consultation } & 47 & 20.3 \\ \text { Chemotherapy/radiotherapy } & 54 & 23.3 \\ \text { Rehabilitation } & 21 & 9.1 \\ \text { [F] Length of stay } & & \\ \text { <1 month } & 85 & 36.6 \\ \text { 1 month } & 61 & 26.3 \\ \text { 2 - 3 months } & 40 & 17.2 \\ 4 \text { - } 6 \text { months } & 17 & 7.3 \\ \text { More than 6 months } & 29 & 12.5\end{array}$

[G] Activities combined with medical trip

$\begin{array}{ccc}\text { Medical treatment only } & 91 & 39.2 \\ \text { Combined with relaxing holidays } & 72 & 31.0 \\ \text { Combined with sightseeing/shopping } & 58 & 25.0 \\ \text { Combined with business } & 11 & 4.8 \\ \text { Total number of respondents } & \mathbf{2 3 2} & \mathbf{1 0 0 . 0}\end{array}$


country of destination for seeking medical services is Germany (24\%) followed by Thailand (20\%), USA (19\%), Singapore (14\%), and India (11\%). The EU and UK was reported by about six percent of the respondents. Data also reveals that about $70 \%$ of medical tourists had traveled abroad multiple times.

One third of the medical treatment seekers visited overseas within one year of time, half of them travelled 1 to 3 years before, while the travelling time of about $17 \%$ for medical purpose was more than three years before.

The medical tourists got the information about the medical destinations by several methods. More than one-third (35.3\%) of the medical tourism destinations were recommended by government and $24 \%$ by doctors. For about one-third of the medical tourist friends were the source of information, whereas some of them got the information from other sources which included internet (6\%), television (0.9\%), and medical tourism guide (2.2\%).

Interestingly, there is no reference to the doctors in the UAE in suggesting the medical destination, which is strange.

Regarding the type of medical treatment or services received, nearly half of the medical tourists (47\%) visited overseas for medication or consultation while $21 \%$ visited for surgery. About $23 \%$ of medical tourists wanted to seek Chemotherapy/ Radiotherapy and a less than ten percent of them visited overseas with the purpose of rehabilitation. The duration of stay was one month or more for more than $60 \%$ of the medial tourists while about $37 \%$ stayed less than one month during their last visit. About $39 \%$ of the respondents stated that their abroad visit was only for the purpose of medical services while rest of them admitted that it was combined with other activities; like relaxing holidays (31\%), sightseeing/ shopping (25\%) and business (5\%).

All said, it is doubtful whether any one of the 5 treatments reported, Table 4 [G] which have been difficult to obtain in the Emirate, yet, the need for providing world-class facilities in the UAE in all branches of medicine and surgery cannot be denied (Table 5 \& Table 6).

\subsection{Satisfactions Level of Medical Tourists}

To test the significance of difference between the satisfaction level and age, education, visiting country for the medical and activities with medical services, ANOVA was applied and the result is presented below in Table 7 .

The Sig. value for age, education, and visiting country is above 0.05 , hence it may conclude that there is no statistically significant difference between level of satisfaction for the medical services and these factors. However, significant difference was observed only with the activities combined with medical services at $5 \%$ level of significance. In other words, it may be concluded that medial tourist visited with the combined activities for relaxation and shopping were more satisfied than those who visited only with the purpose of medical service or if it is combined with business activity (Table 8).

Regarding preferences to travel abroad for medical tourism, if the service becomes available in UAE, nearly half of respondents said they would not travel 
abroad, $23 \%$ said they still willing to travel abroad, and $26 \%$ were not sure.

\subsection{Factors Influencing Decision Making for Seeking Overseas Medical Services}

The mean and standard deviation for all the motivational variables is presented in Table 9. The mean score in the table shows that quality of services, quality of care, qualified and experienced doctors/specialist, advanced technology, and world class facilities were considered the most while making the decision for

Table 5. Chi-square tests.

\begin{tabular}{|c|c|c|c|c|c|c|c|}
\hline \multirow{2}{*}{\multicolumn{2}{|c|}{ Country visited }} & \multicolumn{5}{|c|}{ Type of medical treatment/service } & \multirow[b]{2}{*}{ Total } \\
\hline & & Surgery & Medications & Consultation & $\begin{array}{l}\text { Chemotherapy/ } \\
\text { radiotherapy }\end{array}$ & Rehabilitation & \\
\hline \multirow[b]{2}{*}{ USA } & Count & 13 & 10 & 7 & 15 & 0 & 45 \\
\hline & \% within q9_1 & $28.9 \%$ & $22.2 \%$ & $15.6 \%$ & $33.3 \%$ & $0.0 \%$ & $100.0 \%$ \\
\hline \multirow{3}{*}{ Germany } & Count & 8 & 20 & 11 & 17 & 0 & 56 \\
\hline & \% within q9_1 & $14.3 \%$ & $35.7 \%$ & $19.6 \%$ & $30.4 \%$ & $0.0 \%$ & $100.0 \%$ \\
\hline & Adjusted residual & -1.4 & 1.8 & -0.1 & 1.4 & -2.7 & \\
\hline \multirow{2}{*}{ Thailand } & Count & 6 & 15 & 10 & 2 & 14 & 47 \\
\hline & Adjusted residual & -1.6 & 1.0 & 0.2 & -3.5 & 5.5 & \\
\hline \multirow{3}{*}{ India } & Count & 8 & 5 & 7 & 5 & 1 & 26 \\
\hline & \% within q9_1 & $30.8 \%$ & $19.2 \%$ & $26.9 \%$ & $19.2 \%$ & $3.8 \%$ & $100.0 \%$ \\
\hline & Adjusted residual & 1.3 & -0.9 & 0.9 & -0.5 & -1.0 & \\
\hline \multirow{3}{*}{ Singapore } & Count & 9 & 6 & 5 & 6 & 6 & 32 \\
\hline & \% within q9_1 & $28.1 \%$ & $18.8 \%$ & $15.6 \%$ & $18.8 \%$ & $18.8 \%$ & $100.0 \%$ \\
\hline & Adjusted residual & 1.0 & -1.0 & -0.7 & -0.7 & 2.1 & \\
\hline \multirow[b]{2}{*}{ Others } & Count & 5 & 5 & 7 & 9 & 0 & 26 \\
\hline & \% within q9_1 & $19.2 \%$ & $19.2 \%$ & $26.9 \%$ & $34.6 \%$ & $0.0 \%$ & $100.0 \%$ \\
\hline \multirow{2}{*}{ Total } & Count & 49 & 61 & 47 & 54 & 21 & 232 \\
\hline & \% within q9_1 & $21.1 \%$ & $26.3 \%$ & $20.3 \%$ & $23.3 \%$ & $9.1 \%$ & $100.0 \%$ \\
\hline
\end{tabular}

Table 6. Chi-square tests.

\begin{tabular}{cccc}
\hline & Value & df & Asymp. Sig. (2-sided) \\
\hline Pearson chi-square & $62.726^{\mathrm{a}}$ & 20 & 20 \\
Likelihood ratio & 68.465 & 0.000 & 1 \\
Linear-by-linear association & 0.780 & 0.377 \\
N of valid cases & 232 & \\
\hline
\end{tabular}

a. 5 cells $(16.7 \%)$ have expected count less than 5 . The minimum expected count is 2.35 . 
Table 7. Analysis of variance (ANOVA).

\begin{tabular}{|c|c|c|c|c|c|}
\hline & & Degree of freedom & Mean square & F & Sig. \\
\hline \multirow{3}{*}{ Age } & Between groups & 3 & 0.574 & 0.767 & 0.514 \\
\hline & Within groups & 228 & 0.748 & & \\
\hline & Total & 231 & & & \\
\hline \multirow{3}{*}{ Education } & Between groups & 2 & 0.997 & 1.341 & 0.264 \\
\hline & Within groups & 229 & 0.744 & & \\
\hline & Total & 231 & & & \\
\hline \multirow{3}{*}{ Visiting country } & Between groups & 5 & 1.090 & 1.477 & 0.198 \\
\hline & Within groups & 226 & 0.738 & & \\
\hline & Total & 231 & & & \\
\hline \multirow{3}{*}{$\begin{array}{l}\text { Activities with } \\
\text { medical services }\end{array}$} & Between groups & 3 & 2.043 & 2.803 & 0.041 \\
\hline & Within groups & 228 & 0.729 & & \\
\hline & Total & 231 & & & \\
\hline
\end{tabular}

Table 8. Descriptive statistics (Activities with medical services).

\begin{tabular}{ccccc}
\hline Activities combined with medical services & $\mathbf{N}$ & Mean & Std. deviation & Std. error \\
\hline Medical treatment only & 91 & 4.0000 & 0.95452 & 0.10006 \\
Combined with relaxing holiday & 72 & 4.2917 & 0.75875 & 0.08942 \\
Combined with sightseeing/shopping & 58 & 4.2586 & 0.71477 & 0.09385 \\
Combined with business & 11 & 3.7273 & 1.19087 & 0.35906 \\
Total & 232 & 4.1422 & 0.86366 & 0.05670 \\
\hline
\end{tabular}

Table 9. Descriptive statistics of factors influencing decision making for seeking overseas medical services.

\begin{tabular}{cccc}
\hline & Motivational factors & Mean & S.D. \\
\hline 1. & Advanced technology & 4.46 & 0.701 \\
2. & Accredited by international organization & 4.31 & 0.726 \\
3. & Qualified and experienced doctors/specialist & 4.48 & 0.696 \\
4. & Success rate of treatment is high & 4.28 & 0.723 \\
5. & World class facilities & 4.41 & 0.685 \\
6. & Cost of treatment & 4.38 & 0.722 \\
7. & Quality of services & 4.55 & 0.662 \\
8. & Quality of care & 4.48 & 0.677 \\
9. & Pleasant weather and environment & 4.06 & 0.703 \\
10. & Frequency of direct flights & 4.31 & 0.766 \\
11. & Cost of travelling & 4.37 & 0.732 \\
12. & Great place for relaxation & 4.15 & 0.681 \\
13. & Many tourist places to visit & 4.08 & 0.692
\end{tabular}


travelling overseas for medical services, as it was highly rated at more than 4.4, by the respondents. The cost of treatment, cost of travelling, and accredited by international organization was also highly rated at 4.31 to 4.38 by the medical tourist. However, pleasant weather \& environment and many tourist places to visit were the less rated at 4.06 and 4.08 respectively on a five point scale.

\subsection{Results of Factor Analysis}

To identify the main factors influencing the decision making for selecting the destination for medical services, Exploratory Factor Analysis (EFA) was applied, which allowed for the grouping of the specified measures. First, a reliability analysis was conducted across all the 15 items. The coefficient obtained for Cronbach's a was 0.701 , which is considered to be good. In order to extract the various factors which indicated the motivational factors, Principal Component Analysis was applied on all the variables. The Principal Component Analysis extraction method with varimax with Kaiser normalization rotation method was used to determine the factor loading and communalities.

The Kaiser-Meyer-Olkin (KMO) measure of sampling adequacy was 0.651 in this study, which indicates a good factor analysis. Similarly, Bartlett's Test of Sphericity, another indication of strength of the relationship among the variables was found highly significant at 0.000 .

For the extracted factors, retaining only those variables which had Eigen value more than 1, a total of five factors emerged from the analysis. These fiver factors put together explained 68.0 percent of total variance (Table 10).

After removing the factor loading with less than 0.50, data presented in Table 10 with the communalities and Cronbach's $\alpha$ for each factor. The Cronbach's $\alpha$ for each factor is above 0.7 , which is considered to be good for internal consistency.

The first factor named as "Quality" consists of four items: advanced technology; qualified and experienced doctors/specialist; quality of services; and quality of care and this factor explain $14.8 \%$ of variance. The second factor which is referred as "Attraction" and it comprises of three items: pleasant weather and environment; great place for relaxation; and many tourist places to visit and captured about $14.2 \%$ of variance. The third factor named as "Affordability" accounts for $13.3 \%$ of variance and contains cost of treatment and cost of travelling. The fourth factor, which consists of frequency of direct flights; easy visa process; and travelling time, named as "Accessibility" and it explains about $12.9 \%$ of variance. The fifth and last factor referred as "Image" accounts for about $12.8 \%$. This factor comprises of three items: world class facilities; accredited by international organization; and the high success rate of treatment.

\subsection{Regression Analysis}

Multiple linear regression analysis is used to explore the relationship between dependent variable, "Satisfaction Level (SL)" and independent variables; "Quality", 
Table 10. Principal component factor analysis (varimax rotation), factor loadings, communalities and Cronbach's Alpha.

\begin{tabular}{|c|c|c|c|c|c|c|}
\hline & Factor 1 & Factor 2 & Factor 3 & Factor 4 & Factor 5 & Communalities \\
\hline 1. Advanced technology & 0.806 & & & & & 0.694 \\
\hline 3. Qualified and experienced doctors/specialist & 0.797 & & & & & 0.651 \\
\hline 7. Quality of services & 0.742 & & & & & 0.556 \\
\hline 8. Quality of care & 0.512 & & & & & 0.363 \\
\hline 9. Pleasant weather and environment & & 0.822 & & & & 0.705 \\
\hline 12. Great place for relaxation & & 0.863 & & & & 0.752 \\
\hline 13. Many tourist places to visit & & 0.826 & & & & 0.686 \\
\hline 6. Cost of treatment & & & 0.963 & & & 0.945 \\
\hline 11. Cost of travelling & & & 0.968 & & & 0.941 \\
\hline 10. Frequency of direct flights & & & & 0.786 & & 0.622 \\
\hline 14. Easy visa process & & & & 0.811 & & 0.681 \\
\hline 15. Travelling time & & & & 0.736 & & 0.613 \\
\hline 5. World class facilities & & & & & 0.747 & 0.609 \\
\hline 2. Accredited by international organization & & & & & 0.833 & 0.715 \\
\hline 4. Success rate of treatment is high & & & & & 0.765 & 0.668 \\
\hline Eigenvalue & 2.224 & 2.134 & 1.988 & 1.934 & 1.922 & \\
\hline Variance (\%) & 14.827 & 14.224 & 13.254 & 12.895 & 12.816 & \\
\hline Cumulative variance (\%) & 14.827 & 29.052 & 42.306 & 55.200 & 68.017 & \\
\hline Cronbach's alpha & 0.713 & 0.791 & 0.953 & 0.706 & 0.709 & \\
\hline Overall cronbach's alpha & & & 0.701 & & & \\
\hline
\end{tabular}

"Attraction", "Affordability", “Accessibility", and "Image". Data in Tables 11(a)-(c) show the results of multiple linear regression analysis. It shows the correlation coefficient $\mathrm{R}$ is 0.241 , and coefficient of determination R Square is 0.058 , indicates that about $5.8 \%$ of change in the level of satisfaction is due the relationship with the independent variables which could be characterized as strong. The Durbin-Watson test statistic value is 1.876 and it is well in the acceptable limit to meet the assumption. The F statistic for the regression is 2.782 which shows the relationship between the predictors and dependent variable is significant at $0.05(\mathrm{p}<0.05)$.

The analysis of data in the table presents the standardized regression coefficients (beta) value for all the factors. The tolerance value and the value of variance inflation factor (VIF) related to collinearity statistics is also presented in the above table. The beta value for "Quality" is found 2.874 which is significant at $1 \%$ level of significance $(\mathrm{p}<0.01)$ and have a positive effect on "Satisfaction" of the medical tourists. However, for rest of the factors the beta value does not exert significant positive effect on "Satisfaction" of the medical tourists. Overall, the results indicate that "Quality" is the predictor of "Satisfaction" of the medical tourists. 
Table 11. Multiple linear regression analysis.

(a)

\begin{tabular}{cccccc}
\hline \multicolumn{5}{c}{ Model summary $^{\mathrm{b}}$} \\
\hline Model & $\mathbf{R}$ & R square & Adjusted R square & Std. error of the estimate & Durbin-Watson \\
\hline 1 & $0.241^{\mathrm{a}}$ & 0.058 & 0.037 & 0.84747 & 1.876 \\
\hline
\end{tabular}

a. Predictors: (Constant), Image, Attraction, Affordability, Accessibility, Quality; b. Dependent Variable: SL.

(b)

\begin{tabular}{ccccccc}
\hline \multicolumn{1}{c}{} & \multicolumn{1}{c}{ ANOVA $^{\mathrm{b}}$} & & \\
\hline & Model & Sum of squares & $\mathrm{df}$ & Mean square & F & Sig. \\
\hline \multirow{3}{*}{1} & Regression & 9.990 & 5 & 1.998 & 2.782 & $0.018^{\mathrm{a}}$ \\
& Residual & 162.316 & 226 & 0.718 & \\
\\
Total & 172.306 & 231 & & \\
\hline
\end{tabular}

a. Predictors: (Constant), Image, Attraction, Affordability, Accessibility, Quality; b. Dependent Variable: SL.

(c)

\begin{tabular}{|c|c|c|c|c|c|c|c|c|}
\hline \multicolumn{9}{|c|}{ Coefficients $^{\mathrm{a}}$} \\
\hline & \multirow{2}{*}{ Model } & \multicolumn{2}{|c|}{ Unstandardized coefficients } & \multirow{2}{*}{$\begin{array}{c}\text { Standardized coefficients } \\
\text { Beta }\end{array}$} & \multirow{2}{*}{$\mathrm{t}$} & \multirow{2}{*}{ Sig. } & \multicolumn{2}{|c|}{ Collinearity statistics } \\
\hline & & B & Std. error & & & & Tolerance & VIF \\
\hline \multirow{6}{*}{1} & (Constant) & 2.156 & 0.775 & & 2.783 & 0.006 & & \\
\hline & Quality & 0.336 & 0.117 & 0.195 & 2.874 & 0.004 & 0.905 & 1.104 \\
\hline & Attraction & -0.037 & 0.097 & -0.025 & -0.382 & 0.703 & 0.988 & 1.012 \\
\hline & Affordability & 0.007 & 0.080 & 0.005 & 0.082 & 0.934 & 0.965 & 1.037 \\
\hline & Accessibility & 0.145 & 0.094 & 0.105 & 1.543 & 0.124 & 0.907 & 1.103 \\
\hline & Image & -0.004 & 0.103 & -0.003 & -0.037 & 0.970 & 0.914 & 1.095 \\
\hline
\end{tabular}

a. Dependent Variable: SL.

\section{Discussion}

Although this topic was addressed before in few studies such as Deloitte Survey of the UAE healthcare sector (2011) and YouGov heath survey (2014), we believe that this study focus on understanding the medical tourism trends among UAE people in depth. In this paper, we used a detailed questionnaire exploring medical tourism phenomena among UAE nationals.

In addition, we focused in our study on those people who met the medical tourism definition of travelling abroad mainly to receive medical treatment or surgery and we ignored other categories which come under other definition such as Cross-border medical travel or International patients.

We consider this study important because the majority of participants were graduate and post graduates UAE people who have a leading position in their families.

According to the study results, the preferred country of destination for seeking medical services was Germany followed by Thailand, USA, Singapore, and 
India. Other European countries and UK are also reported by about six percent of the respondents. We conclude that the main reason which stands behind these selections are 1) the advanced technology in some countries such as Germany and USA, and 2) the low cost of treatment in other countries such as India, Singapore, and Thailand. More, we noticed that none of these countries have similar culture and language.

Our study has brought forth good information about the cost of medical tourism trips. a majority of the travelers stayed for more than 1 month in the medical tourism countries. Secondly, a good number of medical tourists travelled abroad more than one time. Thirdly, as many as (nearly 60\%) of the medical tourists combined the medical treatment trip with other activities such as sight seeing and shopping. However, in the business state of the UAE, business doesn't appears to be on the mind of medical tourism from the UAE to world renowned business states as the US, Germany and Singapore.

Furthermore, depending on respondents answers, we can easily conclude that the trend of travelling abroad is increasing among UAE people. Nearly one third of the respondents had travelled abroad in less than one year (2016), while, the rest travelled in more than 1 year (before 2016). That is, there there are repeated medical trips abroad.

The study points out several methods used by the Emiratis to know about medical tourism destinations. Nearly one third of medical tourism destinations were recommended by the government. This could be due to the sponsorship of a good number of medical tourism trips by the UAE government. Also, the second method used to get information and advice was from friends. This method matches the well-known fact about the closeness and trust among the UAE people as individuals, families, and tribes. Some Emiratize depended on doctor's expertise for recommending the suitable medical tourism destinations. Other methods such as internet, news papers, and televisions were not trusted by the Emiratise. In this information age there is no difficulty in deciding upon medical tourist destination.

The most common types of treatment that were sought by Emirati people in medical tourism destinations included medications, chemo/radiotherapy, surgeries, consultation, and rehabilitation.

Also, no statistically significant difference was observed between the level of satisfaction of the medical services and the respondent's age, education, and medical tourism country. However, significant difference was observed only with the activities combined with medical services. Although around $40 \%$ of UAE medical tourists had travelled abroad for medical treatment only, the study shows that those who combined medial tourists with other activities such as relaxation and shopping were more satisfied than those who visited only with the purpose of medical service or if it is combined with business activity.

The study, also, shows that quality of services, quality of care, qualified and experienced doctors/specialist, advanced technology, and world class facilities were considered the most while making the decision for travelling overseas for 
medical services. Other motivational factors including cost of treatment and travelling and accreditation by international organization were also highly rated by UAE medical tourists. Although this may be true about the selected medical tourism destinations, it, somehow, ignore the huge development of health care services in UAE hospitals. This could be due to lack of sharing successful stories with the Emiratis regarding treatment inside the country and lack of internal marketing strategies that target UAE people.

According to the pleasant weather \& environment and many tourist places to visit were among the less rated by the respondents. The finding of the study is that $40 \%$ of medical tourists who travelled abroad looking for quality medical treatment only could explain this.

The result of factor analysis identified 5 variables that were considered by the Emiratis for travelling abroad for medical treatment. Those factors are quality, attraction, affordability, accessibility and image. The Satisfaction Level of medical tourists was found strongly affected with change in any of the 5 variables.

\section{Implications}

We believe that medical tourism phenomenon should be considered by the country's government and health policy makers. This phenomenon should be streamlined with the government strategy to reduce expenses on healthcare and turn any losses on the cost into profits.

We believe that most of the services mentioned by the respondents are available in the UAE hospitals and the health authorities have well improved physician and other healthcare providers recruitment process considering high standardized licensing criteria and examinations.

However, qualifications alone are not enough to attract UAE nationals to receive treatments such as cancer surgeries, and highly specialized eye and bone surgeries in the country's hospitals. We understand the nationals are concerned about how qualified those physicians, are and the need for those physicians to have a good professional history inside the country. This can be done by taking extra steps to reduce health professionals overturn and use smart marketing strategies-remembering that a majority of the UAE nationals trust their friends and believe stories heard from them more than television, newspapers, and the internet.

A such, the UAE government efforts should be to establish world-class hospitals similar to Sheikh Khalifa hospitals in Ras Al Khaymah and Umm Al Quwain, and several private hospitals in different emirates. Other huge hospitals are for completion in the next 2 years or so, namely $\mathrm{Al}$ Ain Hospital and Sheikh Shakhbout Medical City in Abu Dhabi.

In our view, building world-class hospitals and getting international accreditation are the easiest part of the job. The health authorities should ensure those hospitals are managed efficiently by providing high specialized healthcare, and provide satisfactory customer services. The news of which spread fast by the 
word of mouth and experience among the general public. So, it is management, hospital management that emerges as the prime factor in health care and medical treatment.

We think that both public and private sectors should do more to increase UAE nationals awareness about the strengths of UAE health system and the disadvantages of medical tourism abroad on patients and their families and the negative impact of the medical tourism phenomena among UAE people on country economy.

An important question was included in the questionnaire, whether the respondents would still prefer to travel abroad for treatment, if this treatment become available in the UAE?. Nearly a half of the respondents had a positive inclination to this; they said "we prefer not to go abroad travel, if treatment becomes available in the country". We believe that this trend is realistic and matches the increasing level of education and awareness among the younger generation of UAE nationals.

These trends are in need to be boosted by health authorities to build a better healthcare industry in the country.

\section{Limitations}

The study, of course is not the last word of on the medical tourism abroad of the people of the United Arab Emirates, as there are many limitations of the study, such as of time, money, and manpower, data and techniques, as such there is a need for continuous of the problem from time to time.

\section{Conclusion}

The study, on the whole through light on the dynamics of abroad medical tourism of the people of the UAE, is found to be better medical treatment and combines it with other tasks such as shopping, relaxation and relocation. Our final analyses show the relative affluence of the Emiratis which makes the people take a medical journey to other nations guided by cost, quality and time factors.

\section{References}

[1] Choi, W.A., Kim, H. and Lee, S.-C. (2016) Word-of-Mouth in Medical Tourism: The Major Determinant for Emirati Patients to Visit Korea. The Korean Journal of Internal Medicine Korean, 1-3.

[2] de Arellano, R. and Annette, B. (2007) Patients without Borders: The Emergence of Medical Tourism. International Journal of Health Services, 37, 193-198. https://doi.org/10.2190/4857-468G-2325-47UU

[3] Medical Tourism Association Definition (2017). http://www.medicaltourismassociation.com/en/medical-tourism-faq-s.html

[4] Smith, M. and Puczko, L. (2009) Health and Wellness Tourism. Elsevier, Oxford, 101.

[5] Horowitz, M. and Rosensweig, J. (2008) Medical Tourism vs. Traditional International Medical Travel: A Tale of Two Models. International Medical Travel Journal, 
3, 30-33.

[6] Jagyasi, P. (2008) Defining Medical Tourism-Another Approach. Medical Tourism Magazine.

http://www.medicaltourismmag.com/defining-medical-tourism-another-approach/

[7] Carrera, P. and Bridges, J. (2006) Globalization and Healthcare: Understanding Health and Medical Tourism. Expert Review Pharmacoeconomics Outcomes Research, 6, 447-454. https://doi.org/10.1586/14737167.6.4.447

[8] WTO (2013) The General Agreement on Trade in Services. Trade in Services Division, 3. https://www.wto.org/english/tratop_e/serv_e/gsintr_e.pdf

[9] OECD (1989) Trade in Services and Developing Countries. OECD, Paris.

[10] Jorge Augusto Arredondo Vega (1998) The Case of the Mexico-United States Border Area, in UNCTAD-WHO Joint Publication. International Trade in Health Services: A Development Perspective, United Nations, Geneva, 172.

[11] HOPE European Hospital and Healthcare Federation (2015) Medical Tourism. Hope Publications, Brussels, 1-40. http://www.dkgev.de/media/file/21428.Anlage2_9._EUReview_2015.pdf

[12] Anido-Freire, N. (2012) The Emergent Medical Tourism: Advantages and Disadvantages of the Medical Treatments Abroad. International Business Research, 5, 41-50.

[13] Connell, J. (2013) Contemporary Medical Tourism: Conceptualization, Culture and Commodification. Tourism Management, 34, 1-13. https://doi.org/10.1016/j.tourman.2012.05.009

[14] Musa, G., Thirumoorthi, T. and Doshi, D. (2011) Travel Behavior among Inbound Medical Tourists in Kuala Lumpur. Current Issues in Tourism, 15, 525-543. https://doi.org/10.1080/13683500.2011.626847

[15] Lee, C. and Spisto, M. (2007) Medical Tourism, the Future of Health Services. Going for Gold Best Practices in Ed. and Public, Paper No. 7, 1-7. http://bm.nsysu.edu.tw/tutorial/iylu/12th\%20ICIT/07-07.pdf

[16] Woodward, D., Drager, N., Beaglehole, R. and Lipson, D. (2002) Globalization, Global Public Goods and Health, in WHO, Trade in Health Services: Global, Regional and Country Perspectives. Pan American Health Organization, Program on Public Policy and Health, Division of health and Human Development, Washington DC, 3-11.

[17] Herrick, D. (2007) Medical Tourism: Global Competition in Health Care. National Center for Policy Analysis (NCPA) Policy Report No. 304.

[18] Ehrbeck, T., Guevara, C. and Mango, P. (2008) Mapping the Market for Medical Tourism. The McKinsy Quarterly, 1-11.

http://www.heal-wheel-india.com/white-pappers/McKinsey-Report-Medical-Travel $\underline{\text { pdf }}$

[19] Intuition Communication Ltd. (2012) The Medical Tourism Survey 2012. http://intuitionconnect.com/asset_files/TA\%20Medical\%20Tourism\%20Survey m mary\%20and\%20Order\%20Form.pdf

[20] qSample (2012) What Is Driving the Growth in Medical Tourism? http://efti.hhp.ufl.edu/wp-content\%5Cuploads/Medical-Tourism-2012.pdf

[21] Han, H. (2013) The Healthcare Hotel: Distinctive Attributes for International Medical Travellers. Tourism Management, 36, 257-268. https://doi.org/10.1016/j.tourman.2012.11.016

[22] Crooks, V., Whitmore, R., Snyder, J. and Turner, L. (2017) Ensure That You Are 
Well Aware of the Risks You Are Taking...": Actions and Activities Medical Tourists' Informal Caregivers Can Undertake to Protect Their Health and Safety. BMC Public Health, 17, 487. https://doi.org/10.1186/s12889-017-4442-1

[23] Lunta, N., Horsfall, D., and Hanefeld, J. (2016) Medical Tourism: A Snapshot of Evidence on Treatment Abroad, Maturitas, 88, 37-44.

https://doi.org/10.1016/j.maturitas.2016.03.001

[24] Lunt, N., Smith, R., Exworthy, M., Green, S., Horsfall, D. and Mannion, R. (2011) Medical Tourism: Treatments, Markets and Health System Implications: A Scoping Review. The Organization for Economic Co-Operation and Development (OECD). https://www.oecd.org/els/health-systems/48723982.pdf

[25] Deloitte (2008) Medical Tourism. Consumers in Search of Value, Deloitte Center for Health Solutions, 1-28.

https://www.globalwellnesssummit.com/wp-content/uploads/Industry-Research/A mericas/2008-deloitte-medical-tourism-consumers.pdf

[26] Sarwar, A., Yong Gun Fie, D., MHD Sarif, S. and Nikhshemi, S. (2016) On the Ethics of Medical Tourism: An Examination of Patients' Perspectives, (Letter to the Editor). Iranian Journal of Public Health, 45, 688-689.

[27] Meghani, M. (2013) The Ethics of Medical Tourism: From the United Kingdom to India Seeking Medical Care. International Journal of Health Services, 43, 779-800. https://doi.org/10.2190/HS.43.4.k

[28] SPI Group (2014) The Growth of Medical Tourism in the UAE. http://www.theintelligentsme.com/2014/10/the-growth-of-medical-tourism-in-theuae/

[29] Medical Tourism Association (MTA) (2016) Medical Tourism Index. https://www.medicaltourismindex.com/

[30] Gulf News (2016) UAE Leads Globally in JCI-Accredited Organizations. http://gulfnews.com/news/uae/society/uae-leads-globally-in-jci-accredited-organisa tions-1.1912671

[31] Ganji, S. (2015) Hub Healthcare: Medical Travel and Health Equity in the UAE. Sheikh Saud bin Saqr Al Qasimi Foundation for Policy Research, 1-32. http://www.alqasimifoundation.com/admin/Content/File-7122015125423.pdf

[32] Colliers International (2014) Research and Forecast Report. Dubai Healthcare Overview: Growth Potential in a Competitive Market Environment, Q4, 1-16. http://www.colliers.com/-/media/83e76364901e465986cbf44594578c2a.ashx?la=engb 